\title{
Towards a sociology of curiosity: theoretical and empirical consideration of the epistemic drive notion
}

\author{
Ariel Bineth $^{1}$ \\ Accepted: 2 October 2021 / Published online: 8 November 2021 \\ () The Author(s), under exclusive licence to Springer Nature B.V. 2021
}

\begin{abstract}
The article argues for the social production of curiosity. Due its motivating characteristic, curiosity is reconceptualized as an epistemic drive which organizes the social production of knowledge under given socio-historical and local-cultural circumstances. First, historical, philosophical, and sociological literature is reviewed to give a context for the argument. Then a theoretical apparatus is developed considering the emergence, development, and impact of epistemic drives which serves as a foundation for empirical analysis. The second part demonstrates applicability by discussing the problem of economic incentives in scientific research. I argue that scientific projects with little to none immediate economic return have a significant disadvantage in acquiring funding which in turn impacts the mobilization of curiosity in their field. A tendency which systematically yields a disproportionate distribution of knowledge. In conclusion, the article suggests the usefulness of the epistemic drive notion in understanding curiosity as a sociological object.
\end{abstract}

Keywords Curiosity · Economic incentives $\cdot$ Knowledge production $\cdot$ Risk · Scientific research $\cdot$ Sociology of knowledge

When we hear the word 'curiosity', most of us associate a mental picture with it. Maybe it is a picture of a young child discovering the world, or a nosy neighbor peeking over the fence, perhaps an enthusiastic scientist staring into her telescope directed at the evening sky. What is common to all these pictures is the description of an action. Curiosity moves the child to touch the flame, and curiosity keeps the astronomer awake in the dead of night. Then we associate curiosity with an urge to know something, often despite whether that knowledge is good or bad for us. After all, curiosity killed the cat, and curiosity caused the fall of Adam and Eve. Regardless of being good or bad, we also like to imagine curiosity happening to a person.

Ariel Bineth

Bineth_Ariel@phd.ceu.edu

1 Department of Sociology and Social Anthropology, Central European University, Quellenstrasse 51, 1100 Vienna, Austria 
More precisely, we imagine it happening inside a person. It is in the nature of the child to explore the environment, it is the neighbor's habit to be snooping around, and it is the spirit of the scientist which makes her appreciate the constellation of celestial bodies. These are all ideas we attach to the word 'curiosity' without paying much attention. In general, curiosity is a taken for granted expression which is often used as a blanket term. As common sense as these ideas on curiosity are, their origin is deeply rooted in history, where the notion took many different shapes and forms.

From the ancient philosophers up to the modern scientists, the concept has transformed its meaning. For the most part, however, curiosity was shunned as it was identified with prying into matters with which one had no business. This negative attitude has characterized the perception of curiosity in Christian Europe until the birth of scientific thinking has molded it into something desirable and necessary for reaching a greater understanding of the external world. Nonetheless, mixed ideas remain around curiosity. In the academic world, curiosity has preoccupied philosophers contemplating the nature of human beings and the knowledge they possess. Although the topic only recently became popular in contemporary philosophy. Cognitive psychology also treated curiosity extensively, mainly as an emotion and a neurological phenomenon. Common to these dominant approaches of studying curiosity has been a strong sense of individuality which was most interested in how curiosity occurs within the person. However, contrary to our deep-seated habit, what if we start thinking about curiosity, not as internal but social?

This article pursues the idea that curiosity is primarily a social phenomenon. Due to the stringent individualism, this idea strikes as unintuitive. However, I propose that we have good reasons to think about curiosity as a sociological object. Although sociologists have analyzed the circumstances and impact of knowledge production before, curiosity has not received a thorough sociological treatment. The main question I will address is what a sociology of curiosity would be about, and how can it be conceptualized? Throughout this essay, I provide an account of curiosity as an epistemic drive, i.e., a motivating and organizing force propelling processes of knowledge production in society. I argue that curiosity qua epistemic drive organizes knowledge production, emerges, and develops under socio-historical and localcultural conditions, and shapes the social, natural environment. Furthermore, with the epistemic drive approach, I wish to provide a model of curiosity which can be extended to social groups and institutions. Thus, instead of being solely a personal experience, curiosities live a vibrant social life in the form of epistemic drives as they arrange and establish knowledge projects in the social world.

To accomplish this, I develop the argument in two parts. In the first part, I consider the theoretical possibility of a sociological concept of curiosity, while in the second part, I attempt to show its utility. Part I begins laying the theoretical grounding by addressing three significant preconceptions of curiosity held in the popular imagination while discussing historical, philosophical, and sociological contexts. The 'History of Curiosity' addresses the normativity of curiosity by showing how the concept was used with considerably negative or positive connotations throughout different stages in history. The section on the 'Philosophy of Curiosity' dispels the preconception of uniformity with the help of contemporary philosophical literature, which provides a taxonomy of the different kinds of curiosities. The last 
preconception, individuality, is addressed by reviewing how the sociology of knowledge opened up knowledge production as a fundamentally social phenomenon, although it did not address curiosity directly. I attempt to fill this gap by reconceptualizing curiosity as an epistemic drive organizing the social production of knowledge determined by historical and cultural conditions. I break up the description of the idea into the stages of emergence, development, and impact. Each of these segments elaborates on different angles of epistemic drives depending on the level of analysis.

In Part II, I aim to show that the epistemic drive notion of curiosity is a valuable tool for sociological interpretation. For this reason, I present the case of economic incentives in scientific research. The essence of the problem is that scientific projects promising more immediate financial benefits receive substantially more funding than those with less or no short-term profitability. For analysis, I use the categories of 'production research' and 'risk research;' the former aiming to improve economic production while the latter aims to provide risk assessment and harm prevention from technological interventions. With these categories in mind, I present details on global investments addressing climate change and statistics on the US federal research and development funding. These records demonstrate a reluctance to invest in risk research projects, a pattern that is alarming considering the progressing climate crisis. In light of their effect, I propose that economic incentives rather produce epistemic drives manifesting in production research than risk research.

Additionally, I describe and contrast the epistemic drives motivating two different styles of scientific inquiry to show in greater detail how curiosity for productive ends gains its prevalence in the current economic incentive structure. The last section of the article deals with the idea of pure curiosity-driven research, or basic research, which is theoretically free of external interest. By presenting a first-hand field report on a science-industry conference at a basic research institution, I indicate that even curiosity-driven research manifests in epistemic drives with a production orientation. Given the dependence of scientific research on financial sponsorship, I conclude that economic incentives produce production-oriented epistemic drives that motivate and organize mainstream scientific practice. This tendency systematically immobilizes the realization of risk-curious research projects, leaving both decision-makers and the public with a restricted understanding of the risks that technologies pose to nature and society.

Overall, I make a case for the social production of curiosity to deepen our understanding of what organizes knowledge production in society. While I tried to make my argument as comprehensive as possible, it is far from complete interpretation. I merely prepared the ground, outlined how a sociological interpretation of curiosity would look like, and provided an empirical case to test my ideas. The main purpose of this work is to provoke us into asking better questions regarding the social aspect of curiosity. Naturally, there will be some unanswered questions that could not fit this work. I will indicate these directions for future elaboration. If my account is convincing that it is possible and worth thinking about curiosity as a sociological object, I consider my attempt successful. With that, let us begin the journey towards the sociology of curiosity. 


\section{Part I - Towards a sociology of curiosity}

\section{History of curiosity}

The first preconception we must address is normativity, which assumes that curiosity is either a virtuous or sinful notion. Following the work of historian Philip Ball, the history of curiosity reveals a diverse past. Ball argues that curiosity has never meant just a single thing, but the meaning the word took mirrored the historical times in which it stood (2014). In general, we can distinguish two opposite interpretations of curiosity. The first one is negative, which sees curiosity as a vice, the second is positive, which sees curiosity as a virtue. This is especially important because normative meanings may involuntarily sneak into our discussion, and neither of these views suffices for sociological interpretation.

In 350 B.C., Aristotle famously wrote, "All men by nature desire to know" (1984). Ever since the Greek philosopher, the origin, nature, and qualities of curiosity have occupied a principal position in the minds of thinkers such as Plutarch, Aquinas, and Saint Augustine. Later on, the idea of curiosity was cemented in the modern scientific imagination as the mysterious origin of knowledge. It is a puzzling sensation hard to explain for Albert Einstein. He wrote, "Curiosity has its own reason for existence. One cannot help but be in awe when he contemplates the mysteries of eternity, of life, of the marvelous structure of reality" (Miller, 1955).

Curiosity is generally conceptualized as a desire for knowledge or understanding. Nonetheless, in the popular view, it is a sensation sometimes likened to hunger which naturally emerges within humans, and it is only possible to extinguish through an inquiry of some sort. Inquiry, of course, results in acquiring knowledge, a process assumed to be so central to humans as a species that it is even reflected in the Latin designation homo sapiens or wise man. The centrality of curiosity in distinguishing humans as species was noticed by Thomas Hobbes, "Desire, to know why, and how, CURIOSITY; such as is in no living creature but Man; so that Man is distinguished, not only by his Reason; but also by this singular Passion from other Animals; ... [curiosity] which is a Lust of the mind, that by a perseverance of delight in the continuall and indefatigable generation of Knowledge, exceedeth the short vehemence of and carnall Pleasure" ([1651]1985).

If the capability to create knowledge is what makes us human, then curiosity - this carnal desire to know - must be a characteristic equally central to our identity. However, this perspective of curiosity is relatively recent, considering the records of history. In fact, for the greater part of recorded history, at least until the seventeenth century, curiosity was not a trait held in high regard (Daston \& Park, 1998). Often curiositas (from the Latin cura to care) was understood as prying into matters one had no business with which led the believer to a dangerous path. The Bible explains, "with much wisdom comes much sorrow; the more knowledge, the more grief" (New International Version 2011, Ecclesiastes 1:18). Contrary to what his oft-cited quote suggests, Aristotle thought that curiosity (periergia) has a minor role to play in philosophy, as he understood it as an erratic nosiness. Instead, he felt the sense of wonder (thauma) inspired one to seek knowledge consistently. 
The influential Christian philosopher Saint Augustine saw curiosity as a "malady" (morbo) that drove the folly off the path of faith and into the ungodly matters of magical arts ([ca. 400]1982:55). This allure of heresy remained popular until the Renaissance, when an unprecedented interest started to build up around the idea of curiosity. Historian Neil Kenny, surveying academic publication patterns in sixteenth century Europe, identified a sudden increase after the $1650 \mathrm{~s}$ after which curiosity has remained a common topic of dissertations on the European continent (2004). The medieval academic world dominated by the scholasticism of Christianized Aristotelian deductive logic started to be challenged by a new, primarily nonacademic perspective that appreciated the natural world's minute details through observation and later experiments. Curiosity began to change its meaning from nosiness into things that God did not want people to see into anticipation of understanding the work of God in its vast physical totality. As the $18^{\text {th }}$-century philosopher Robert Boyle said, "whatever God himself has been pleased to think worthy of his making, its fellow-creature man should not think unworthy of his knowing" (1772:13).

Discovering the wonders and workings of the natural world brought practical benefits, as well as occasions of entertainment. The rulers of the seventeenth century kept natural philosophers, sages, and courtiers to provide ideas for military advantage, but also to show spectacles in the form of machines, beasts, and other peculiar findings what Ball calls the "theater of curiosity" (2014:49). The word "curious' came to mean not just a state of being, but it also designated objects worthy of attention, careful examination, and even collection. Renaissance princes collected the most diverse and fascinating things from nature in a Wunderkammer with the primary intention to impress their guests. These cabinets of curiosities were the predecessors of today's museums.

The wealthy gentlemen of Britain started not just collecting natural objects, but they systematically categorized them to display their learnedness to their contemporaries. Soon these privileged social circles formed the Royal Society of London under the aegis of Francis Bacon's utopian vision of The New Atlantis (1624), which championed an enlightened society of peace, prosperity, and faith brought by knowledge of nature. However, curiosity was not central in the Baconian ethos of science which strived for the systemic observation and analysis of natural occurrences (natural histories) to deduce fixed laws revealing the underlying mechanisms of the world. According to Ball, Bacon's science was a "knowledge machine" less interested in the sense of wonder than the systematic interpretation of the physical world into one final synthesis (2014:103).

Today, curiosity plays a vital role in scientific inquiry, which has brought technological advancement on an unprecedented scale. This immediate impact of technology on our life makes curiosity the lifeblood of the concept of 'progress,' an idea of the indefinite betterment of the human condition. This idea resonates in the words of Robert Aymer, the past director-general of the European center for particle physics in Geneva, when he said, "The Large Hadron Collider is a discovery machine. Its research program has the potential to change our view of the universe profoundly, continuing a tradition of human curiosity that's as old as mankind itself" (Collins, 2008). Ball takes this decidedly recent narrative of curiosity - 'the motor of 
uninterrupted progress' - as one interpretation among many over time. Instead, he appeals for a perspective of curiosity as a notion with different "meanings and values attached" according to a "particular and contingent history" (2014:398).

Curiosity came to embody very different interpretations throughout history that served different purposes, inciting greater faith in God or technological progress. Although I aim to distance value terms in the sociological analysis, they play an essential role in showing how different historical circumstances give rise to different normative understandings of a similar phenomenon.

\section{Philosophy of curiosity}

The second preconception we must address is the uniformity of curiosity. Here we turn to philosophy to appreciate the analytical dissection of the many diverse types of curiosities. It is surprising how novel the contemporary philosophy of curiosity is. As the previous section outlined, many philosophers used some idea of curiosity to a lesser or greater extent; however, the first thoroughly analytical treatment of the topic was completed by Ilhan Inan in his The Philosophy of Curiosity (2017). ${ }^{1}$ Among the fruits of the new philosophical investigations is the importance of the motivating characteristic of curiosity and its many diverse manifestations.

There are several definitions of curiosity, with notable differences between them. However, curiosity is traditionally understood as "the desire for knowledge or understanding" (Miščević, 2018). Generally, the nature of curiosity as a desire has been supported by most thinkers and cognitive psychologists. The sensuality of curiosity has deep roots in the history of philosophy, which the brief historical survey showed. More interesting are the recent psychological explorations of curiosity conceptualizing it as an emotion (Silvia, 2006). Emotions, as the name suggests, are drives that make an individual inclined towards action. As curiosity is the spring of motivation for epistemic action, this becomes the heart of the matter. According to Miščević, curiosity manifests the desire for knowledge and drives the organization of all other cognitive faculties to reach a truth. He calls this the motivating virtue account of curiosity (2018). The motivating aspect will be central in our sociological account because it indicates that curiosity is a location of agency and change.

Miščević makes relevant distinctions to set different types of curiosities apart. These differences address the preconception of uniformity and reveal the many shapes curiosity can take. We can rely upon Miščević's account of an initial taxonomy distinguishing curiosities along four main properties: 1) Target, 2) Quality, 3) Value Status, and 4) Bearer (forthcoming) (Table 1). ${ }^{2}$ The Target of curiosity 1) concerns the object of interest or the objective the inquiry wishes to achieve. First, the target can have extrinsic (applicability) or intrinsic (pure theory) goals or a mix of the two. The scope of the investigation can be depth (intensity) or width (range) oriented depending on the aim. Finally, Miščević distinguishes between the linkage

\footnotetext{
1 See also Inan 2018

${ }^{2}$ Miščević notes that this is a taxonomy under construction. Therefore, I will only present the essential aspects of curiosity pertaining to our topic.
} 
of curiosity, whether it is connected (systematic inquiry), perhaps part of a research program, or disconnected (individual occurrence).

Then, we may describe the 2) Quality of curiosity which concerns the style, strength, and time variables. The style can variate between pessimistic and optimistic ends. Miščević uses the contrast between falsificationism and verificationism in the philosophy of science as an example. He notes that radical optimism can lead to forms of dogmatism, while extreme pessimism can lead to excessive skepticism (Miščević, 2018:47). Furthermore, the strength of curiosity might be described from mild to intense, and the time can range from short to long term. The 3) Value Status of curiosity considers moral dimensions. For example, Nazi prison experiments are corrupted while Jonas Salk's polio vaccine experiments are upright.

Additionally, we can also distinguish the importance of the target of curiosity, for example, making a polio vaccine or developing a new flavor for a candy bar. Unfortunately, Miščević does not address how the determination of the value status of a curiosity is contingent on the shared value system of social groups and the difficulty of thoroughly evaluating something as good or bad. The last key attribute is the 4) Bearer of curiosity. It designates the characteristics of the entity that possesses curiosity. Miščević divides this into individual and social aspects. Furthermore, considering the social organization of curiosity, one may speak of institutionalized or noninstitutionalized curiosities. This is of remarkable importance to the sociological approach, but Miščević offers little direction at this point. Although he realizes the categorical difference an institutional curiosity can make, he does not engage in a detailed discussion due to his focus on individual varieties. Therefore, among other things, the task ahead is to outline the social and institutional aspects of curiosity.

In general, I find the taxonomic distinctions of curiosity very useful. They help distinguish between different kinds of curiosity and help us avoid the preconception of uniformity, which results in using the concept as a blanket term. Furthermore, the idea of curiosity as motivation is vital since only through this aspect can we see the notion as a force that induces a change in the social world. This change not only occurs in the social organization of knowledge production, but the consequences of the produced knowledge are equally transformative as they justify social action. For this reason, I take the motivating characteristic as a foundation for the sociology of curiosity. However, the general shortcoming of the philosophy of curiosity, at least from a sociological aspect, is the ongoing treatment of the idea from an individualistic perspective that does not explain social or institutional cases.

\section{Curiosity and the sociology of knowledge}

I consider individuality as the last preconception of curiosity that we must shed before formulating a sociological account. Individuality has dominated philosophical and psychological analysis, but it also connotes a sense of naturality with curiosity, which assumes that it is exclusively a biological phenomenon. Sociology is set against these individualist traditions of thinking. The sociological understanding of knowledge poses that ideas develop in relation to social groups and institutions; epistemic processes and perceptions are determined by socio-cultural factors 
(e.g., class, race, gender, socio-economic status, nationality, age, etc.). Thus, it investigates the degrees, patterns, and manners of social group influence (McCarthy, 2007). The central thesis of the sociology of knowledge - the causal relationship of social structure and knowledge - counteracts the individualist approach. While the sociology of knowledge establishes knowledge as a socially dependent object, it carries a mixed legacy.

Having its first breakthrough in the 1930s, the Hungarian sociologist Karl Mannheim developed a Wissensoziologie to explain the differing truth claims of Fascism, Communism, Traditionalism, and Liberalism ([1929] 1936). While Mannheim's theoretical abilities were praised, he was criticized for lack of empirical use. The second wave of sociology of knowledge came in the 1960s during the ideologically turbulent Cold War. Peter Berger and Thomas Luckmann pursued a phenomenological approach to the sociology of knowledge in The Social Construction of Reality (1966). Although Berger and Luckmann had an original approach and their work became a classic at the time, the buzz around the sociology of knowledge cooled off. Peter Hamilton, who formulated a short history and criticism of the topic, emphasized the lack of empirical applicability as the key component of the apparent letdown of the sociology of knowledge (1974). I do not share the extent of Hamilton's view because these theoretical formulations did provide a better perception and vocabulary to describe the broader issue at hand. However, this did not include the idea of curiosity per se.

Arguably, a more fruitful attempt of studying the social aspects of knowledge production came from the sociology of scientific knowledge, which started in the 1970s by a group of academics at the University of Edinburgh. This interdisciplinary Science Studies Unit inaugurated the 'strong programme' which adhered to the maxim that no piece of scientific knowledge becomes accepted only because it is true. Instead, scientific knowledge is contingent on socio-historical context, dependent on the negotiation processes of the local context, and it demands constant work to keep knowledge legitimized (Daston, 2009:804). This path of inquiry has led to the interdisciplinary field of Science and Technology Studies (STS) analyzing the social structures and institutions behind scientific knowledge production. More importantly, contrary to the earlier theoretically oriented pioneers of sociology of knowledge, STS focuses on the local as described by the empirical. Through its collection of case studies, STS wishes to bring transparency to the scientific process. Historian of science Lorainne Daston says, "Science was shot through with social interests and political struggles; it was the job of science studies to lay them bare" (2009:806).

Interestingly, the topic of curiosity is absent from science studies literature as well. Even the flagship journal of STS, the Social Studies of Science, has not published any articles on curiosity yet. Although, I do not believe this absence mirrors the discipline's awareness of the issue. Any investigation of society seeking to answer questions relating to knowledge production must have, if not an explicit, but an underlying assumption about curiosity. For instance, some research projects in STS deal with how research topics are selected in various scientific fields. The pharmaceutical industry has been one of the most prominent examples. Several scholars pointed out how research is excessively motivated by market interests, leading to 
issues such as the under research of tropical diseases or the potential bias of industry-sponsored clinical trials (Dumit, 2012; Petryna, 2009).

More importantly, alongside the empirical science studies popular in AngloSaxon academia, the theory of the sociology of knowledge gained substantial contributions from the German sociologist Nico Stehr. The foundation of Stehr's sociology was laid in Knowledge Societies (1994) which proposed that the existing and transforming knowledge practices provide the backbone of modern society. Placing the notion of knowledge in the center, Stehr analyzed the role of knowledge in different areas such as science, politics, and economics. What was common to all his investigations is Stehr's understanding of knowledge as "a capacity to act," which puts things in motion. He emphasized, knowledge was not simply a "model of reality" but a "model for reality" which allows certain social groups to influence and shape the world through the means of knowledge "work" (Adolf \& Stehr, 2017). In Stehr's sociology, the concept of knowledge is not just factual information but a socially produced object encapsulating the possibility of social action. Agency, therefore, is deeply intertwined with how knowledge is produced, disseminated, accessed, and applied.

Yet the importance of action is not new. It was emphasized by Emile Durkheim, who wrote, "At the origin of the process of knowledge, the idea to be checked is the idea of something to be done" ([1955] 1983:48). We can notice how this definition of knowledge as action intersects with curiosity as motivation-both place agency in the center of epistemic actions. But Stehr's sociological theory focuses on knowledge as a social product and does not accentuate the preceding phases. However, curiosity precedes knowledge, in the same way motivation precedes action. Therefore, the question of how the motivation for acquiring knowledge comes to be is one waiting to be answered.

\section{The epistemic drive notion}

Throughout discussions on historical, philosophical, and sociological literature, we have arrived at the point to formulate a proposition for the sociology of curiosity. So far, I have argued that the preconceptions of normativity, uniformity, and individuality of curiosity must be addressed to clear the ground for this attempt. The work we have done to highlight these preconceptions can also guide us in elaborating the notion. Therefore, the sociological idea of curiosity proposed here should be valueneutral, divergent, and above all, rooted in social causes. Furthermore, I take the view of curiosity as motivation as the starting point of my account. For that reason, I propose the sociological understanding of curiosity as a motivation to organize the processes of knowledge production. To indicate this explicitly social aspect of curiosity, I will refer to it as an epistemic drive.

Drive is a traditionally psychological concept that refers to underlying emotional forces within an individual. It may seem counter-productive to use it in a sociological treatment that seeks explanation beyond the individual's inner world. However, I wish to bridge this divide by showing that curiosity experienced on the individual level in the form of a drive is, in fact, the end result of a constellation of social 
relations the person is emerged in. Therefore, an epistemic drive is not merely individual and emotional but social and structural. By taking this into account, we notice how the motivation to create epistemic products is emerging under the pressure of specific social conditions. Furthermore, as I will show later on, some epistemic drives become paradigmatic to the extent that they contribute to producing the prevailing social order. Using this understanding of curiosity, we can conceptualize individuals as being curious as well as abstract, social entities such as communities, organizations, and institutions. In this sense, we can see how drive emerges as a sociological concept. In light of this, I offer a sociological definition of curiosity: An epistemic drive organizing knowledge production that emerges and develops under socio-historical and local-cultural conditions and shapes the social, natural environment.

The epistemic drive notion, however, operates with supposition that we can more or less isolate various forms curiosities and study their particular characteristics. Since this implies a sense of unity that is hard to substantiate why carry on with the approach? Why not just be satisfied with a term that recognizes epistemic motivation but does not try to artificially box it in by turning it into a distinct entity? As I indicated before the purpose of this essay is to lead us to ask better questions about the social aspects of curiosity. Then we should approach the epistemic drive notion as a working metaphor rather than strict ontological description. However, the drive metaphor can lead us to better questions and new insights about curiosity at least in two ways. First, by constructing curiosity as a unified drive we go against the habit of conceiving of it as black-box that is inherently ambiguous. The drive framework forces us to ask questions about particularities (e.g., target, quality, value status, bearer) and provokes us into explicating these characteristics with social explanations. Second, as all metaphorical exercises the drive notion is productive by charting where it works and where it breaks down. Accordingly, we may leave with new conclusions regarding our attempt to socially theorize curiosity.

The outline of the sociology of curiosity presented here will contain three parts: emergence, development, and impact. These three units represent different angles on curiosity, and they bring various questions to the analysis. The part on emergence investigates the social origins of curiosity in individuals or institutions. At the center of this stage is the question of why individuals or institutions become interested in those exact things in that exact way they become curious about? Why do individuals or institutions want to answer question $\mathrm{X}$ and not question $\mathrm{Y}$, and how did they formulate their question? Ultimately, questions of emergence are about identifying specific social triggers or influences of curiosity.

The part on development concerns the progressive interaction between curiosity and the social environment. Epistemic drives are rarely static entities. Instead, they have changing trajectories where they experience variations in their target, quality, value status, or bearer over time. What we are interested in is the role of socio-historical, local-cultural factors in this variation. What are the epistemic drives which get to be realized and end up creating knowledge products? Why did those epistemic drives succeed while others faded or died out?

The last part concerning the impact of curiosity deals with the relationship of epistemic drive, knowledge product, and the impact of knowledge on the social, 
natural environment. This segment brings out the political dimensions of curiosity by asking about the consequences of large-scale knowledge-producing practices. Given the real-world implications of these epistemic practices, who are the winners and the losers of dominant curiosities? If not all curiosities can be realized equally, should we change that? If we do, then are we limiting the freedom of science? Since epistemic motivations extend through historical time and social space, the stages of emergence, development, and impact cannot be entirely dissected. They may occur and interact simultaneously; however, we will discuss them separately for greater clarity.

\section{Emergence}

All epistemic drives must come into existence at a point in time. The sociological proposition here is that the social environment in which the individual or institution exists has a significant effect on the emergence of the epistemic drive. What kind of elements do we mean under the term social environment? The social environment signifies the cluster of sociological characteristics an individual or institutions occupies or possesses and the network of relationships they exist within. I use the term 'socio-historical' to refer broadly to social, political, economic, and environmental conditions at a given historical time. By 'local-cultural,' I refer to the network of agents at a social locality, the cultural norms which describe their relations, and the resources they have at their disposal (e.g., time, financial capital, technical apparatus, scientific capital, etc.). This list of social conditions is not exhaustive; however, they signify critical categories of analysis. The socio-historical and local-cultural conditions influence the different attributes of epistemic drives, as in their target, quality, value status, and bearer. For example, a social movement can intensify interest towards racial inequities, or the lack of resources may restrict the epistemic drive only to the short term.

There are different triggers of curiosity without which the motivation to conduct an inquiry would have never emerged. Although, triggers can only work alongside relatively static background structures. For example, the existing bodies of knowledge serve as background structures that limit the possibility of questions to ask. Then a trigger of curiosity would be a more immediate environmental stimulus, such as the need to generate shareholder value. As mentioned before, pharmaceutical companies tend to ignore researching tropical diseases because they lack financial incentives. When pharmaceutical companies decide to dedicate resources to developing a drug, they conduct market research to make sure that they make the best use of their investment. In this case, market interests and a company's financial resources are essential in a specific curiosity's emergence. The general proposition suggested here assumes that a similar set of social structures and conditions will yield similar epistemic drives, perhaps, not to a fully deterministic extent, but at least to a reasonably parallel one. This implicates that there can be a limit to what an individual or an institution can be curious about. If social structures determine epistemic drives, then the epistemic drives which are not necessitated by the social environment cannot emerge. This would explain the lack of pharmaceutical interest in tropical diseases. Additionally, there might be a limit to what one can be curious 


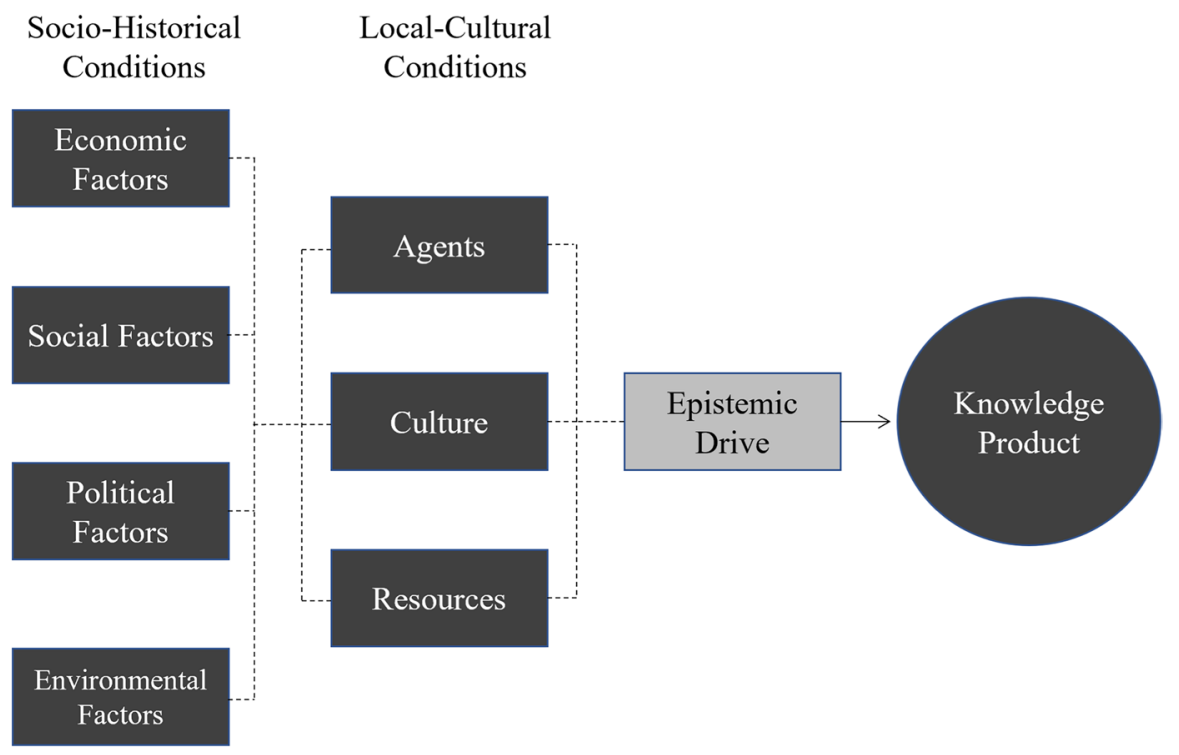

Fig. 1 The social production of epistemic drives

about at a given historical time in a specific social location, a limit beyond which lies the unthinkable, an area which cannot be targeted as an interest due to the limitations of what is reachable epistemically. ${ }^{3}$ On the whole, the emergence of epistemic drives is tied to the existing socio-historical and local-cultural conditions; this is what I call the social production of epistemic drives (Fig. 1).

\section{Development}

After emergence, we can talk about the development of epistemic drives. We may start from the assertion that epistemic drives are developing in relation to the surrounding social environment. I propose understanding epistemic drives in society with trajectories extending and developing through social space and historical time through which their attributes can modify. After a specific epistemic drive emerges, it has continuous interaction with its immediate social environment. According to this milieu, the characteristics of the epistemic drive may alter in different directions. In other words, we can say that no epistemic drive in society can occur in isolation from the social environment. The sociological question is then to explore the circumstances of specific cases of epistemic drives and uncover their development trajectories with explanations for changes. Such an analysis assumes that these trajectories rarely develop linearly without changing some element of their attributes. Instead of a pure rational model of knowledge production, the sociological

\footnotetext{
${ }^{3}$ The similar notion of episteme is developed by Michel Foucault in The Archeology of Knowledge (1969). 


\section{Immobilization Mobilization}

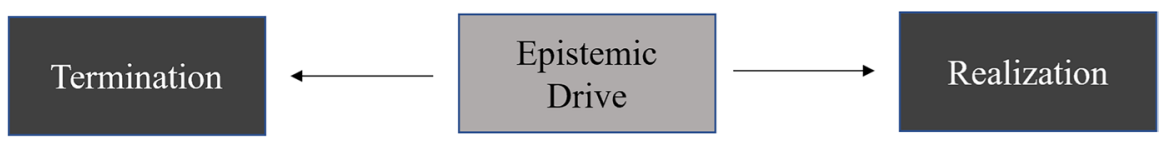

Fig. 2 Two general trajectories for epistemic drives

Table 1 Miščević's taxonomy of curiosities

\begin{tabular}{lll}
\hline Target & Goal & Extrinsic/Intrinsic \\
& Scope & Depth/Width \\
& Linkage & Disconnected/Connected \\
Quality & Style & Pessimistic/Optimistic \\
& Strength & Mild/Intense \\
& Time & Short Term/Long Term \\
Value Status & Moral Status & Bad/Good \\
& Importance & Low/High \\
Bearer & General & Individual/Social \\
& Social & Non-Institutional/Institutional \\
\hline
\end{tabular}

investigation of epistemic drives looks for points of friction, obstruction, or discontinuity as markers of relevant social influence.

Given the proposition of nonlinear development, what kind of changes can we distinguish when examining the trajectories of epistemic drives? The main categories of trajectory development are mobilization and immobilization. Suppose we accept that epistemic drives are an effort to form projects with the aim of knowledge creation. In that case, we may say mobilization moves epistemic drives towards the realization into knowledge form. On the other hand, immobilization is a development towards the termination of an epistemic drive (Fig. 2). It is worth thinking in these terms because there are indications that some curiosities are preferred over others, meaning that not all epistemic drives can get realized with an equal chance. The specific context of social structures and the power relations running through them enable some epistemic drives while disabling others.

These relatively consistent patterns of epistemic drive mobilization and immobilization can be envisaged with the analogy of cultivating a garden. Immobilization occurs to those epistemic drives which do not fit some condition of their social environment. These end up being ignored, neglected, or even weeded out, depending on the manner of immobilization. Often, these epistemic drives do not have the chance to flourish into knowledge form. A direct and intensive immobilization, or suppression, of epistemic drives, can be found when a government forbids researching certain areas. This induces a chilling effect resulting in the retrenchment of academic interest in the matter. Alternatively, the direct and intensive mobilization of an epistemic drive, or stimulation, occurs when excessive resources are made available to research a given matter. Therefore, the social environment can influence the rate of development of epistemic drives. Interestingly, stimulation may also bring about 
suppression inadvertently if we consider how certain ways of knowledge production dominate society, flood the channels of knowledge dissemination, therefore, drowning out alternative approaches.

However, this is not necessarily the end of the social life of curiosity. An epistemic drive can either cease or trigger and transform into a new epistemic drive when it achieves realization. For instance, both the stimulation and suppression of epistemic drives can lead to the multiplication of them. A stimulation multiplies epistemic drives due to the availability of resources, while suppression can multiply curiosities as a reactionary act. However, stimulation results in a greater quantity of epistemic drives, suppression can alter trajectories towards more intensive curiosities as a reaction to the hostility of the environment. Michel Foucault also commented on the reactivity of curiosity regarding the intellectually numbing effect of mass media. Foucault said, "I believe that people react; the more one convinces them, the more they question things. The mind isn't made of soft wax. It's a reactive substance. And the desire to know [savoir] more, and to know it more deeply and to know other things increases as one tries to stuff peoples' heads" (1997:325). Together, mobilization and immobilization illustrate how epistemic drives develop trajectories in an interaction with the socio-historical and local-cultural social environment.

Although an issue arises when we consider epistemic drives as discreet entities. Our approach assumes that we can positively identify where one epistemic drive begins and ends, even if there are multiple at work at the same time. The problem of demarcation prompts us to ask how we can successfully isolate an epistemic drive for analysis. Our method of demarcation can develop along the characteristics we have already identified in epistemic drives, such as target, quality, value status, and bearer. In other words, we can ask what is target of this curiosity, is it pessimistic or optimistic, is its scope range or depth oriented, etc.? We should mention that these characteristics of epistemic drives are in development which should further propel us asking more and better questions about curiosities.

\section{Impact}

The last perspective of curiosity in need of analysis is its eventual impact on the social world. As we have assumed at the beginning, curiosity is a drive that motivates knowledge production. We have to consider the consequences that the produced knowledge creates in the environment in which it is applied. Specifically, how can we describe the relationship between the epistemic drive and the social impact of knowledge? This question is essential because knowledge has a valuable status in modern societies. The different knowledge production and dissemination processes are often described as knowledge economies where knowledge becomes a commodity (Adolf \& Stehr, 2017; Sismondo, 2018). Of course, knowledge is intangible; however, the value inherent in epistemic products is their interpretive ability which provides a model for the world around us. Those who possess knowledge can make decisions with a greater degree of certainty and predictability. In short, knowledge 
Fig. 3 Epistemic drive as motivation for social action

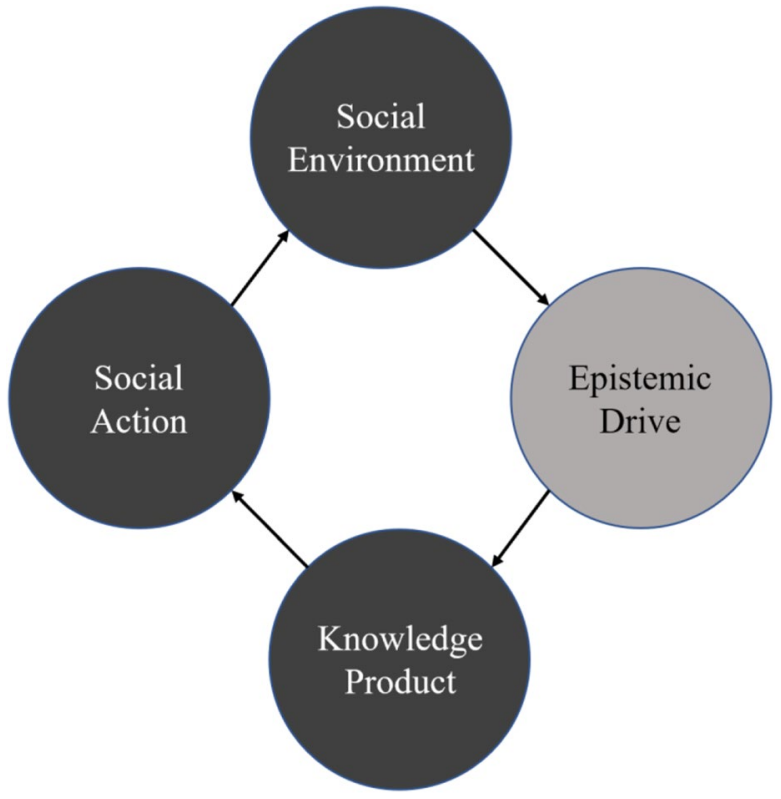

allows agents to organize their actions in a meaningful way that serves their interests. It affords them "the capacity to act" (Stehr, 1994).

Furthermore, knowledge production allows agents to diminish or raise the importance of existing concepts, make connections between them, and even create new meanings. The production and rearrangement of bodies of knowledge become a tool that can pick at and shape understanding and perception. Through these processes, dominant interpretations of the world emerge, which become paradigms, a generally accepted frame of reference. This happens at the expense of other possible interpretations of the world, which would produce different social actions depending on their content. In this light, the impact of epistemic drives becomes quite relevant. Curiosity demarcates the target of interpretation. It serves as a locus of agency by organizing epistemic projects. It creates knowledge products. Ultimately, social action is taken based on this knowledge, which benefits some and disadvantages others. We can chart a cycle of how epistemic drives emerge from their social environment, and by motivating knowledge production, they also shape it (Fig. 3).

The issue is that epistemic drives attain greater mobilization through existing structural conditions in society, such as the circumstances of given political and economic systems. Some of these epistemic drives are not just directly stimulated but are generally valued higher by the norms of a society. Given that epistemic drives produce knowledge products, the most knowledge will be produced through the most prevalent epistemic drives. Those epistemic drives that are deemed less important cannot have access to adequate resources for realization and cannot influence the prevailing understanding of a subject matter. Consequently, these unpopular epistemic drives also have less sway in determining the direction of social action. Asking who are the winners and losers of prevalent epistemic drives is crucial because 
the entrenched patterns of mobilization and immobilization of epistemic drives play a role in reproducing social inequalities. To recite a previous example, those who suffer from tropical diseases are disadvantaged by the prevalent curiosity in researching diseases common in Europe and North America. This demonstrates that epistemic drives' emergence and development have real-world consequences that are not isolated from the existing relations of power. If knowledge is power, then the drive to produce knowledge is the source of power. Coming full circle, the impact of epistemic drives shapes the very conditions of the social environment from which it emerged.

I provided an initial outline for understanding what epistemic drives are and how they operate in society. So far, we have only theoretically reflected on the epistemic drive notion and have not put these ideas to test with an empirical case. I already hinted at how economic and market interests affect epistemic drives. Therefore, in the second part of the article, I will describe the influence of economic incentives on scientific research to test the epistemic drive notion.

\section{Part II - Economic incentives and scientific research}

\section{Funding science}

We have a theoretical outline of curiosity as a sociological object, but how can these ideas be applied in academic practice? After establishing the theoretical possibility of a sociology of curiosity, we should consider if such a framework is meaningful enough to interpret empirical cases. To do this, I bring the problem of the role of economic incentives in scientific research.

The problem is the following: It is acknowledged that scientific research is a capital-intensive process that demands sponsorship, but some research projects receive more funding than others which creates a hierarchy. Towards the top of this hierarchy are scientific projects yielding more immediate economic returns. These are usually concerned with discovering or bettering production processes by technological implementations; I call this production research. On the opposite, projects with less immediate or fewer economic returns are mitigated, even if they have a valuable intellectual or humanitarian contribution. Among these are research projects assessing the risks of technological interventions and their social, environmental impact (e.g., unintended consequences). Some examples are environmental science, technology assessment, or conservation biology; I call them collectively risk research projects. While I understand that many projects show both or more characteristics, this generalization is utilized to illustrate how social conditions - in this case, economic ones - produce a specific type of epistemic drive.

Since they have different aims, production and risk research have significant differences in how they conduct science. Production research is pragmatic and optimistic, while risk research is speculative and pessimistic. Both inquiries are operating on scientific grounds given the knowledge and apparatus they employ, yet they are curious about different things; production or prevention, respectively. Hence, according to Miščević's taxonomy, production and risk research constitute different 
kinds of epistemic drives. Since economic incentives play a crucial role in determining which projects are funded, we can infer that financial incentives also determine what institutions get curious about. Therefore, economic incentives stimulate a specific kind of curiosity. How can we show this? The assessment of research funding is an exceptional tool for understanding what types of scientific projects enjoy greater access to resources. This analysis assumes that the distribution of research funding reflects the importance of epistemic drives for the funding institutions. Here we see that production research prevails in the spending charts. However, this has significant negative consequences.

The neglect of risk research and the advancement of production research creates an environment where risk discovery and assessment are valued and pursued less. But ignoring accumulating and interacting risk factors leads to technology-induced harms, sometimes drastic and irreversible (e.g., climate change). Risk research must receive more funding to reduce these harms, yet immediate economic returns are deemed more important. Ultimately, I propose that the economic incentives behind funding science largely determine the emerging epistemic drives in actual scientific practice.

\section{Reluctance to invest in risk}

Previously, I assumed a hierarchy of research funding where the values of production and immediate economic return are higher than prevention and long-term investments. This is not surprising since the flow of financial capital towards shortterm return investments has been one of the significant trends of the increasing financialization of the global economy. Nonetheless, this phenomenon has also been observed in the flow of international investments to address climate change. According to environmental journalist Sophie Yeo, "climate cash" is disproportionately flowing into projects concerned with energy production - such as solar power plants and hydropower stations - that are inadequate to limit temperature rise (2019). Yeo notes how these enterprises are often related to private investors in wealthier countries, which drains the cross-border flow of funds. At the same time, the Intergovernmental Panel on Climate Change cautions that "spending on adaptation efforts is particularly low" (Yeo, 2019). Generally, plans which would limit the impact of climate change receive some twenty times less funding. Yeo indicates how these projects prioritize adaption efforts such as building coastal defense systems, reforestation and cutting carbon emissions which are not attractive investments for the private sector. Furthermore, Yeo states, US fossil-fuel ventures received around $\$ 400$ billion in subsidies in 2018 , more than double what renewable resources got. Seeing these global investment trends, we might expect a similar pattern in funding scientific research.

Looking at the distribution of the US federal funds for research and development (R\&D) confirms expectations (NSF, 2018). After consulting the official 2018 surveys, we can notice that the field of Engineering received almost three times as much funding for research as the field of Environmental Sciences. The difference is staggering between the National Aeronautics and Space Administration (NASA) 
that received around $\$ 2$ billion for $\mathrm{R} \& \mathrm{D}$, and the Environmental Protection Agency (EPA), which only received $\$ 700$ thousand. Yet, these numbers are overshadowed by the Department of Defense, which received an incredible $\$ 53$ billion for research in 2018, making it the most funded agency. Other risk-oriented US agencies are also underfunded compared to the overall resources their department have. For example, the nuclear waste cleaning Environmental Management received \$38 million in the Department of Energy (received total $\$ 13$ billion). The Agency for Toxic Substances and Disease Registry received \$2.8 million in the Department of Health and Human Services (total $\$ 40$ billion). The most funded risk-oriented agency was the US Geological Service (\$593 million) which spends more than $60 \%$ of its budget on issues like "adaptation, resource allocation and planning to address drought, flooding, wildfires and related risks affiliated with change in land use" (USGS, 2019). However, around \$84.1 million of its budget is still dedicated to "research and assessments on the occurrence, quality, supply, and use of national and global mineral and energy resources" (USGS, 2019). Investing in risk is not too attractive. Epidemiologist Dennis Carroll's research institution investigating zoonotic disease threats got entirely defunded by the US government in 2019, just before the COVID-19 outbreak. Carroll said, "It's not just the US government but governments at large and the private sector-we don't invest in risk [...] So part of the challenge is getting lawmakers and investors to invest in risk" (Berger, 2020). The reluctance to invest in risk justifies a hierarchy of research funding that reflects the strong influence of economic interest in research.

One might object that even though production research is more attractive for investment, this is not a problem since it was through pioneering new technologies that the benefits of modern life came into existence. While this is true for the welloff segments of the world, we know that along with new technologies, new problems arise which impact the least well-off the most. Then a society that devalues investing in risks is partly blind to the threats they pose and to those who suffer the consequences. We need to look no further than current assessments of the climate crisis. More than two centuries after the First Industrial Revolution, the world faces the damages done by the increase in the global mean temperature. According to a new estimate, if the global mean temperature increases by 3 Celsius degrees, approximately 7 billion will be at risk of heatwaves, near 4 billion at risk of water stress, near 1 billion experience power reduction, 2 billion suffer crop yield change, and over 1 billion must bear their habitat degrade (Beyers et al. 2018). The risks of climate change are incomprehensibly significant, and there is an overwhelming scientific consensus that it is the result of human technological intervention. Although risk research became more institutionalized over the last thirty years by NGOs, policymakers, and social movements, industrial interests still mostly overlook it (Dunlap \& Catton, 1994; McCright \& Dunlap, 2010). Nevertheless, by marginalizing risk research, the structure of industrial society is endangering the very environment it depends on.

Social scientists anticipated that the symptoms of self-destruction would bring growing awareness to the sources of risks. The German sociologist Ulrich Beck developed a critique of technology-oriented science in Risk Society (1992). He argues for the increasing presence and awareness of technology-induced risk in 
modern societies. According to Beck, Western societies are going through a process of "reflexive modernization," an increased understanding of the quality and extent of the risks technologies produce (1992:155). As an example, Beck cites the environmental movement, which since then has only grown with recently Greta Thunberg rallying people in 150 countries through her Fridays for Freedom protests. One of the critical problems with emerging risks, states Beck, is that they remain largely invisible and their exposure depends on scientific investigation; they "require the 'sensory organs' of science - theories, experiments, measuring instruments -to become visible or interpretable hazards at all" (1992:27). Even in the face of increasing risks, technoscientific rationality keeps getting the most resources, but there is no effective answer. Beck sees this as a problem "systematically grounded in the institutional and methodological approach of the sciences to risk" (1992:59). While Beck points out the key issue, the source of the problem is not just the sciences approach to risk but the socio-economic structures that incentivize and fund research to make science available in the first place.

Since scientific research is a capital-intensive enterprise, it depends on sponsors for the provision of adequate resources. In general, sponsors come from the public or private sector. However, regardless of social positioning, funding research is usually seen as an investment with an expected return. The dependence of scientific research on sponsorship and the economic benefits sponsors demand have been criticized as narrowing down the creativity of research and limiting the freedom of science. This issue has been tied to grants culture in the public sector, where proposed projects must conform to a certain area and style of research dictated by the government. US President Dwight D. Eisenhower lamented how government grants become "virtually a substitute for intellectual curiosity" (1961).

On the other hand, private sector funding poses the threat that the curiosity of research projects is increasingly tied to interests dictated by the market. In the financialized global economy, both government grants and market interest are increasingly moved by short-term economic incentives. They serve as stimulants for a specific kind of epistemic drive, which manifests in production research. To better understand the issue, let us apply our theoretical framework and describe the epistemic drives behind production and risk research.

The epistemic drive motivating production research corresponds with what Ulrich Beck calls "technoscientific curiosity," an inquisitiveness in the "utility for production" (1992:60). We can describe the target of technoscientific curiosity (or production-oriented epistemic drive) as extrinsic in applicability, especially in discovering more efficient technological solutions for production processes. This pragmatism of technoscientific curiosity manifests in finding out how to make something work. Noting the quality, this kind of epistemic drive is primarily optimistic, which resonates with the relentless hopefulness of modern capitalism's 'don't take no for an answer' philosophy. The strength and timeframe largely depend on specific cases; however, institutions are often the bearers of this kind of epistemic drive, especially in places where research directly supports the production chain.

In contrast with production research, we should also chart the epistemic drive motivating risk research to appreciate their differences. Risk research demands a 
different style of scientific practice than its productive counterpart. Risk curiosity (or risk-oriented epistemic drive) is an epistemic drive that has an intrinsic, theoretical value as it aims to uncover an interconnected network of risk factors and their threats to the social and natural environment. Instead of immediate application, this epistemic drive is skeptical by asking what can go wrong and what are the consequences? In its quality, risk curiosity manifests a pessimistic style as it needs to assume the worst cases which can develop from technological threats. It is also case dependent regarding strength and time frame-ideally, the more robust and more prolonged, the more comprehensive. The bearers of this epistemic drive are also institutions, but instead of private industrial entities, they tend to be public civil organizations.

We can notice the key differences between the two orientations of these epistemic drives. Given the influence of economic incentives, it is self-explanatory why technoscientific curiosity enjoys predominance. Since production research and risk research has qualitatively different aims, they demand different styles of investigation, which are made possible by different kinds of curiosities. By looking at the funding patterns, we can see that production research is more abundant in resources than investigations of risks. In turn, this disproportionate spending habit also affects epistemic drives as it leaves little resources to realize risk-curious projects. Above all, it is not just projects left underfunded but entire styles of thinking, unique ways of organizing research, and original perceptions of the world are sidelined. Riskoriented epistemic drives are routinely immobilized by the norms of the existing funding patterns primarily defined by economic incentives. The lack of opportunity to realize risk curiosity results in decreased emergence and the general impotence of these epistemic drives. If well-supported, they could lead to novel, complex knowledge products on understanding the threats of technological practices on communities and the natural world. This is not to say that there is no active risk research going on, only it is significantly fewer and smaller than those for improving production. However, the stimulation of technoscientific curiosity is also counterproductive as it increasingly becomes restricted and compartmentalized for achieving narrow, practical purposes. Hence the negative impact of an intensively mobilized production-oriented epistemic drive is the lack of detailed understanding of how technological interventions generate new societal threats. Overall, we can trace how the need for short-term economic return is mobilizing production-oriented epistemic drives while immobilizing risk-oriented ones. Since understanding the world demands a heterogeneous pool of knowledge, a collection of different maps, we are at loss of those kinds of epistemic drives that do not get the chance to realize.

\section{Pure curiosity driven research}

Seeing how deeply economic incentives determine epistemic drives, we might wonder if we could eliminate financial incentives from funding science. Then curiosities would have an equal chance to flourish. This is the hope what the purely curiositydriven basic research promises. Natural scientists demand basic research as they notice the encroachment of immediate political and economic incentives on their 
practice which is evident from the increasing focus on applied research. Chemistry Nobel Laureate Ahmed Zewail was concerned about this issue when he warned, "The curiosity-driven approach seems increasingly old-fashioned and underappreciated in our modern age of science... Some believe that more can be achieved through tightly managed research - as if we can predict the future. I believe this is an unfortunate misconception that affects and infects research funding" (Ball, 2014:405). The cure for restoring the freedom of scientific investigation seems to be in the unbound possibilities of pure curiosity-driven basic research. The idea is that if only the conditions of pure curiosity in research can be guaranteed by expelling political and market interests, scientific research would become more fruitful. Perhaps basic research being untainted from politics and the market holds the key towards an unbiased direction in epistemic output? Can basic research truly represent a neutral curiosity, free of external interests? The following first-hand field report at a basic research institution suggests otherwise. By reporting on the contents of a scienceindustry talk, I proceed to show that even basic research ends up manifesting a relatively homogenous pattern of epistemic drives determined by economic incentives. It might be curiosity-driven but it is the same kind of curiosity that drives it.

\section{The case of IST Austria}

On the $19^{\text {th }}$ of November 2019, the Institute of Science and Technology (IST) in Austria organized a science-industry talk titled Capturing Serendipity. IST Austria's flush Raiffeisen Lecture Hall hosted the event from 6 to $9 \mathrm{pm}$. The elegantly arranged occasion aimed to bring together leading scientists and entrepreneurs under one roof to discuss best practices in seizing technological innovation for commercial purposes. Researchers, entrepreneurs, inventors, and investors presented themselves in sophisticated outfits as they busily chatted away at the reception, sipping wine and enjoying a three-course dinner. The entire occasion was designed to network and to do business. I was mesmerized by the elite atmosphere of the venue, as well as the selection of desserts. Nonetheless, what I heard at the main event raised questions about whether basic research is as free as it claims to be.

The main event presented a panel of influential industrialists and showcased the institute's leading research projects. In light of this fact, I should not be surprised that there was not a case of risk research among the presentations. Regardless of being a science-industry talk, I find it unsettling that no projects even mentioned the climate crisis because even a pessimist could have expected some projects in the spirit of environmental modernization (i.e., solving the climate crisis with new technology). Still, none of the presenters found this aspect necessary to voice. Instead, these scientists presented their projects appealing to productive prospects, valiantly projecting their voice to the furthest corners of the room - some more successfully than others - trying to impress the honorable audience. This confidence permeated all the voices of the conference, creating a cacophony of optimism. To get a sense of IST Austria's scope of research, I will summarize the projects of the panelists' who presented.

The first researcher to present was Georgios Katsaros (1), a physicist working on quantum computer technology. In his presentation, he emphasized the 
paradigm-shifting possibilities in quantum computing as it allows calculations that standard computers cannot handle. The second in line was physicist Maria Ibáñez (2), who created metamaterials by using nanocrystals as artificial atoms. She stressed that nanocrystals could give greater control over physical matter, leading to countless commercial applicabilities. One of them is a fabric that generates electricity through the heat of the body. The third presenter was Krzysztof Pietrzak (3), a computer scientist occupied with improving cryptographic technology. One of his main projects is creating a sustainable cryptographic system for Bitcoin because the secure operation of the digital currency uses up more electricity than some countries do. The fourth presenter was computer scientists, Bernd Bickel (4), who improves digital fabrication methods by creating algorithms to model and simulate material designs. He presented the success of his recent project (funded by the European Research Council), which was software generating mold designs based on the digital simulation. This allows businesses to produce products by plastic molding efficiently. The fifth researcher to present was neurobiologist Gaia Novarino (5), whose team investigates the genetic basis and neurological functioning of conditions such as epilepsy and autism. She was very optimistic about creating pharmacological treatments to these predispositions, although there is a growing movement against medicalizing aneurotypically functioning individuals. The last presenter was Harold Vladar (6) the CEO of Ribbon Biolabs, a company selling synthetic DNA at the newly built corporate office park on the IST Austria campus. Resembling a business pitch, Vladar exhibited his company's competence in supplying synthetic DNA for future clients.

This birds-eye-view of the showcase illustrates the scientific portfolio of IST Austria. Indeed, the institute is very innovative as all the described projects push the limits of existing scientific knowledge and technological capabilities. After acknowledging innovativeness, the fact confronts us that all of these scientific projects are being conducted in the name of production research, as they aspire to find new means of enhancing production and establishing greater control over the environment. Production orientedness is evident in project 2 (meta-materials), 3 (digital finance), 4 (plastic item production), 5 (pharmaceuticals), and 6 (biotechnology). However, project 1 (quantum computing) also entails production enhancement, albeit in more indirect terms.

Furthermore, all six projects present new means of establishing greater control over the environment. The example of meta-materials is a very literal instance of this point. On the other hand, none of the undertakings evaluates the adverse effects of technological intervention or environmental impact based on the presentations. Therefore, they cannot be categorized as projects of risk research. Project 5 seems like an exception because developing new drugs involves elaborate testing for side effects. Nonetheless, since the project's goal is to establish control over the environment (i.e., neurological conditions) and its result will be used to produce more financial capital, it is still considered production research. Not to mention, none of the projects emphasized a significant environmental dimension. Based on these indications, it is reasonable to claim that IST Austria is primarily focused on production research. 
Why was there no presentation of risk research if basic research theoretically offers the ability for all types of scientific projects? Perhaps, only the commercially attractive projects were showcased? Indicatively, searching IST Austria's website, I found no reference to researching risk assessment or prevention at the institute. One cannot even claim risk research is commercially unimportant because, for instance, the anticipation and prevention of the effects of climate change can save billions of euros on damages. Given this fact, it appears the reluctance to invest in risk runs deep. My brief assessment reveals that pure curiosity-driven research at IST Austria means research principally with a production orientation. If we were to speak in terms of curiosity, then we may say that the epistemic drive cultivated at the institution correlates with technoscientific curiosity. To reiterate, the target of technoscientific curiosity is primarily to find more efficient means of production. That can mean several things, from reducing production costs by, for example, a new molding technique or it can mean inventing a new meta-material.

Furthermore, the optimism of technoscientific curiosity was audible in the presentations, and it was also captured by the opening speech of Iris Rauskala, Federal Minister of Education, Science and Research of Austria, who stated that "exploitation is the institution's guiding principle." Therefore, we can see that there is a particular kind of institutional epistemic drive seems to be prevalent at IST Austria. We should appreciate that technoscientific curiosity need not be the dominant type of epistemic drive at the institution. For instance, we can see how some research institutions give space for risk curiosity. In theory, scientific investigations can be motivated by different epistemic drives. Yet, those concerned with productive targets seem to prevail in practice, even at a research institution dedicated to pure, curiosity-driven research.

\section{Conclusion}

I wondered if it is possible and meaningful to conceptualize curiosity sociologically. I dealt with the theoretical possibility in the first part of the article. I addressed the common preconceptions of normativity, uniformity, and individuality of curiosity to prepare the ground for a non-normative, diverse, and above all, social interpretation. Fundamentally, I located the sociological core of curiosity in its motivating characteristics. Curiosity becomes social as it motivates agents to organize epistemic projects, which inevitably occur in relation to a social world. However, I also proposed tracing the emergence and development of curiosity to specific social origins. From these reflections, I formulated curiosity as an epistemic drive that emerges in, develops, and impacts the social environment under socio-historical and local-cultural conditions. I described how the social environment could mobilize or immobilize epistemic drives, which significantly impact different segments of society and the environment.

In the second part, I attempted to show that the epistemic drive notion allows us to meaningfully reflect on certain sociological cases, such as the effect of economic incentives on scientific research. Appealing to divergent funding distributions, I established that scientific projects promising short-term financial returns 
are preferred over scientific projects with long-term or lesser profitability, such as studying the risks of technological interventions. Consequently, the reluctance to invest in risk implies the immobilization of risk-oriented epistemic drives, even in the face of the dangers of the climate crisis. In the article's final section, I shared a report of a recent science-industry conference in Austria to argue that even what is supposed to be an environment for pure curiosity produces a series of investigations with a similar kind of epistemic drive motivating them. This curiosity is primarily interested in achieving some form of economic reproduction. Hence, even a supposedly free research environment cannot be untouched by external, social influences which shape its epistemic output. I concluded that economic incentives extensively influence the emergence and development of epistemic drives, in this case, to the detriment of risk curiosity.

Without question, the epistemic drive notion needs further development and exploration. However, there are unique possibilities and, as a direction for future research, I would like to mark a few points. I have been arguing for a determinative relationship between social structures and epistemic drives. However, the extent of this determination is still case-dependent. Therefore, it would be interesting to see how epistemic drives operate in different professional fields where knowledge production plays an important role (e.g., politics, public policy, law, education, natural sciences, social sciences, etc.). It would be worth examining how much agents develop and adapt their curiosities to meet the prevalent curiosity standards in these specific fields. In other words, how are paradigmatic epistemic drives restricting the emergence, development, and impact of marginalized curiosities? For example, how is reflexivity or critical thinking limited in certain institutions with specific political or economic goals in mind, or how does an institution successfully encourage and sustain various epistemic drives? Also, what are the institutional limits of promoting diverse epistemic drives? For instance, organizations may ask to think outside of the box, but it is sociologically telling and rarely explained when it is too much outside of the box. Overall, theorizing the role of institutional cultures on epistemic drives have notable potential for future development.

Coming to the end of our journey, what can we take from this brief inquiry into the sociology of curiosity? Although much exploratory ground has been covered, I believe I managed to point out that curiosity, described as an epistemic drive, is at least a thought-provoking contribution to explaining society's knowledge-producing practices. Because of the complex arrangements of cognitive division of labor in modern societies and the magnitude of influence these epistemic organizations have, it becomes necessary to ask what they are interested in, why they are interested in it, and how they came about being interest in that exact thing. Also, who benefits or suffers from that interest? Here, the epistemic drive notion of curiosity can come as a valuable tool to focus our analysis. It allows us to conceptualize curiosity as embodying diverse attributes that change over time under the influence of social and cultural conditions. In the final analysis, the epistemic drive notion always suggests that the direction of knowledge production is not a choice of 'pure curiosity,' but bound to specific social conditions. As said in the beginning, if I could convince that curiosity is a meaningful sociological object, I 
consider my attempt successful. We might want to revisit our approach to the idea of curiosity to revise its imminent possibilities and limitations by appreciating the many social ties enabling its birth and vibrant life, or at other times, its quiet demise.

\section{Declarations}

Conflict of interest There is no conflict of interest to declare.

\section{References}

Adolf, M., Stehr, N. (2017). Knowledge: Is knowledge power? Second Edition. Routledge, Taylor \& Francis Group.

Aristotle. (1984). Metaphysics, Book I. edited by J. Barnes. NJ: Princeton: Princeton University Press. Bacon, F. (1624). The New Atlantis. Watchmaker Publishing.

Ball, P. (2014). Curiosity: How science became interested in everything.

Beck, U. (1992). Risk society: Towards a new modernity. Sage Publications.

Berger, K. (2020). The man who saw the pandemic coming. Nautilus. Retrieved April 3, 2020 (http:// nautil.us/issue/83/intelligence/the-man-who-saw-the-pandemic-coming).

Berger, P. L., \& Luckmann, T. (1966). The social construction of reality: A treatise in the sociology of knowledge. Anchor Books.

Boyle, R. (1772). Considerations touching the usefulness of experimental natural philosophy. edited by T. Birch.

Byers et al. (2018.) Global exposure and vulnerability to multi-sector development and climate change hotspots. Environmental Research Letters, 13(5):055012.

Collins, G. P. (2008). Large hadron Collider: The discovery machine. Scientific American. Retrieved June 5, 2020 (https://www.scientificamerican.com/article/the-discovery-machine-hadron-colli der/).

Daston, L. (2009). Science studies and the history of science. Critical Inquiry, 35(4), 798-813.

Daston, L., \& Park, K. (1998). Wonders and the order of nature: 1150-1750. 1 (paperback). Zone Books.

Dumit, J. (2012). Drugs for life: How pharmaceutical companies define our health. Duke University Press.

Dunlap, R. E., \& Catton, W. R. (1994). Struggling with human exemptionalism: The rise, decline and revitalization of environmental sociology. The American Sociologist, 25(1), 5-30.

Durkheim, E. (1955). Pragmatism and sociology. Cambridge University Press.

Eisenhower, D. (1961). Farewell address. Retrieved June 7, 2020 (https://www.americanrhetoric.com/ speeches/dwightdeisenhowerfarewell.html).

Foucault, M. (1997). Ethics: subjectivity and truth. edited by P. Rabinow. New Press.

Hamilton, P. (1974). Knowledge and social structure (RLE Social Theory): An introduction to the classical argument in the sociology of knowledge. Routledge.

Hobbes, T. (1985). Leviathan. Penguin Books Limited.

Holy Bible, New International Version. (2011) https://biblehub.com/niv/ecclesiastes/1.htm

Inan, I. (2017). The philosophy of curiosity. First issued in paperback. Routledge, Taylor \& Francis Group.

Inan, I. (2018). Curiosity, truth, and knowledge. in The Moral Psychology of Curiosity, edited by I. Inan, L. Watson, D. Whitcomb, and S. Yigit. Rowman \& Littlefield.

Kenny, N. (2004). The uses of curiosity in early modern France and Germany. Oxford University Press.

Mannheim, K. (1936). Ideology and Utopia. Harcourt Brace \& World.

McCarthy, E. D. (2007). Sociology of knowledge. Pp. 2482-85 in The Blackwell Encyclopedia of Sociology, edited by G. Ritzer. John Wiley \& Sons, Ltd. 
McCright, A. M., \& Dunlap, R. (2010). Anti-reflexivity: the American conservation movement's success in undermining climate change and policy. Theory, Culture and Society, 50(3), 100-133.

Miller, W. (1955). Einstein quoted in life magazine. May 2, 65.

Miščević, N. (2018). Curiosity, its objects and varieties. in The Moral Psychology of Curiosity, edited by I. Inan, L. Watson, D. Whitcomb, and S. Yigit. Rowman \& Littlefield.

Miščević N (Forthcoming). Curiosity: The Central Epistemic Virtue.

NSF. (2018). Survey of federal funds for research and development I NCSES I NSF. Retrieved May 10, 2020 (https://www.nsf.gov/statistics/srvyfedfunds/\#tabs-2).

Petryna, A. (2009). When experiments travel: Clinical trials and the global search for human subjects. Princeton University Press.

Reiss, J., \& Kitcher, P. (2009). Biomedical research, neglected diseases, and well-ordered science. Theoria, 24(3), 263-282.

Saint Augustine. [ca. 400]1982. Confessions. Penguin Books.

Silvia, P. J. (2006). Exploring the psychology of interest. Oxford University Press.

Sismondo, S. (2018). Ghost-Managed Medicine: Big Pharma's Invisible Hands. Mattering Press.

Stehr, N. (1994). Knowledge societies. Sage.

USGS (2019). "USGS 2019 President's budget request.” Retrieved May 10,2020 (https://prd-wret.s3-uswest-2.amazonaws.com/assets/palladium/production/s3fs-public/atoms/files/Fact\%20Sheet\%20-\% 20USGS_0.pdf)

Yeo, S. (2019). Where climate cash is flowing and why it's not enough. Nature, 573(7774), 328-331.

Publisher's note Springer Nature remains neutral with regard to jurisdictional claims in published maps and institutional affiliations. 